\title{
Optimization and Validation of a Rapid Method to Determine Citrate and Inorganic Phosphate in Milk by Capillary Electrophoresis
}

\author{
J. M. Izco, M. Tormo, A. Harris, P. S. Tong, \\ and R. Jimenez-Flores \\ Dairy Products Technology Center \\ California Polytechnic State University \\ San Luis Obispo, 93407
}

\section{ABSTRACT}

Quantification of phosphate and citrate compounds is very important because their distribution between soluble and colloidal phases of milk and their interactions with milk proteins influence the stability and some functional properties of dairy products. The aim of this work was to optimize and validate a capillary electrophoresis method for the rapid determination of these compounds in milk. Various parameters affecting analysis have been optimized, including type, composition, and $\mathrm{pH}$ of the electrolyte, and sample extraction. Ethanol, acetonitrile, sulfuric acid, water at $50^{\circ} \mathrm{C}$ or at room temperature were tested as sample buffers (SB). Water at room temperature yielded the best overall results and was chosen for further validation. The extraction time was checked and could be shortened to less than $1 \mathrm{~min}$. Also, sample preparation was simplified to pipet $12 \mu \mathrm{l}$ of milk into $1 \mathrm{ml}$ of water containing $20 \mathrm{ppm}$ of tartaric acid as an internal standard. The linearity of the method was excellent $\left(\mathrm{R}^{2}>0.999\right)$ with $\mathrm{CV}$ values of response factors $<3 \%$. The detection limits for phosphate and citrate were 5.1 and $2.4 \mathrm{n} M$, respectively. The accuracy of the method was calculated for each compound (103.2 and 100.3\%). In addition, citrate and phosphate content of several commercial milk samples were analyzed by this method, and the results deviated less than 5\% from values obtained when analyzing the samples by official methods. To study the versatility of the technique, other dairy products such as cream cheese, yogurt, or Cheddar cheese were analyzed and accuracy was similar to milk in all products tested. The procedure is rapid and offers a very fast and simple sample preparation. Once the sample has arrived at the laboratory, less than 5 min (including handling, preparation, running, integration, and quantification) are necessary to determine the concentration

Received February 22, 2002.

Accepted March 27, 2002.

Corresponding author: R. Jimenez-Flores; e-mail: rjimenez@ calpoly.edu. of citric acid and inorganic phosphate. Because of the speed and accuracy of this method, it is promising as an analytical quantitative testing technique.

(Key words: citric acid, phosphate, milk, capillary electrophoresis)

Abbreviation key: CCP = calcium colloidal phosphate, $\mathbf{C E}=$ capillary electrophoresis, $\mathbf{C T A B}=$ hexadecyltrimethylammonium bromide, $\boldsymbol{f}=$ response factor, IS = internal standard, KHP = potassium hydrogen phthalate, MWCO $=$ molecular weight cut off, PDC = 2,6-pyridinedicarboxylic acid, p.s.i. = pound square inch, $\mathbf{S B}=$ sample buffer.

\section{INTRODUCTION}

Approximately half of the calcium and inorganic phosphate of milk occurs in the form of a colloidal calcium-phosphate-citrate complex intimately associated with the phosphoproteins (McGaan et al., 1983). Although minerals make up less than $1 \%$ of the total milk composition, mineral content is critical to the buffering capacity of milk and, subsequently, is an essential variable in functional changes such as cheese yield, gel strength, coagulation time, heat stability, and rate of $\mathrm{pH}$ change in milk products during presentation (Kirchmeier, 1980; Srilaorkul et al., 1989; Emmons et al., 1993; Lopez-Fandiño et al., 1998).

The primary buffering factors in milk are soluble phosphate, calcium colloidal phosphate (CCP), citrate, and casein (Unnikrishnan et al., 1982; Lucey et al., 1993a; Singh et al., 1997). The impact that citrate and phosphate salts have on the functional properties of milk is directly related to their equilibrium and their interactions with the casein micelle. Calcium phosphate, found in milk serum and in casein micelles, is a critical factor for the integrity and behavior of the casein micelle (Holt, 1997). The quantity of phosphate may be useful for classifying cheeses on basis of the concentration of $\mathrm{PO}_{4}$ per gram of protein. This would provide more information on how the cheese has been produced and could give a better indication of cheese 
structure than the total mineral content of cheese (Lucey et al., 1993b).

Also, the quantity of phosphate and citrate is very important because their distribution between soluble and colloidal phases of milk and their interactions with milk proteins are important factors in the stability of dairy products (Swaisgood, 1985).

The analyses of these compounds are currently performed by a variety of analytical techniques. The analysis of citrate in milk may be carried out by enzymatic or gravimetric methods (AOAC, 1995), whereas the universal method to determine $\mathrm{PO}_{4}$ is by the reaction of Pi with molybdate to form a blue complex, which can be easily measured at $820 \mathrm{~nm}$ (IDF, 1987). These methods require complicated reactions and are tedious, and the results of the analysis often are unknown for hours. Therefore, an easy and rapid method to analyze these compounds would be a great benefit.

Capillary electrophoresis (CE) has emerged as a powerful separation technique. It has high resolution and efficiency and offers great potential as a rapid detection and quantification method (Izco et al., 1999). The fact that phosphate and citrate can be charged (using $\mathrm{pH}$ values higher than their respective $\mathrm{pK}_{\mathrm{a}}$ values) would suggest that they could be separated by CE. By applying a negative voltage, the anions migrate toward the detector situated at the anode end of the capillary. However, phosphate and citrate have little or no UV absorbance, and the detection must be accomplished with indirect UV by using a background electrolyte. Recently, a CE method to simultaneously analyze the 11 organic acids most frequently studied in dairy products has been developed (Izco et al., 2002). Because of the sensitivity of $\mathrm{CE}$, we have been able to dilute milk up to 100 -fold with sample buffer in a manner that other organic acids present in milk (e.g., acetic, lactic, pyruvic, orotic) did not interfere with the determination of citrate and/or phosphate.

The aim of this work was to develop a rapid CE method for the simultaneous determination of citrate and inorganic phosphate in milk. Various parameters affecting analysis including type, composition, and $\mathrm{pH}$ of the electrolyte, and sample extraction have been optimized. Its versatility in analyzing citrate and phosphate in some other dairy products was also investigated.

\section{MATERIALS AND METHODS}

\section{Instrumentation}

All the experiments were performed with a Bio-Focus 3000 Capillary Electrophoresis System (Bio-Rad Laboratories, Richmond, CA), consisting of a photo-diodearray detector and two 32-position carousels (inlet and outlet). The system was controlled by a computer equipped with a Bio-Focus 3000 software for data collection and analysis. All fused-silica capillaries $(75 \mu \mathrm{m}$ i.d.) used in this work were purchased from Bio-Rad.

\section{Reagents}

Monobasic potassium phosphate anhydrous (99.8\%) was obtained from Sigma (St. Louis, MO), citric acid anhydrous (99.7\%) and tartaric acid were purchased from Fisher Scientific (Pittsburgh, PA). Ultrapure wa$\operatorname{ter}(18.2 \mathrm{M} \Omega)$ prepared by treating deionized water with a Barnstead/Thermolyne System (Dubuque, IA) was used to prepare all solutions. The reagents used to prepare other sample buffers tested in this work such as sulfuric acid, ethanol, or acetonitrile were obtained from Aldrich (Milwaukee, WI). The reagents used to prepare the running buffers assayed were analytical or reagent grade: hexadecyltrimethylammonium bromide (CTAB), potassium hydrogen phthalate (KHP), and sodium hydroxide were purchased from Sigma (St. Louis, MO, USA); 2,6-pyridinedicarboxylic acid (PDC) was obtained from Aldrich (Milwaukee, WI). Ammonium molybdate (Sigma) and ascorbic acid (Fisher Scientific) were used to prepare the reagent used for the colorimetric method to analyze phosphate.

\section{Electrophoretic Procedures and Conditions}

Unless specified otherwise, the final conditions used to analyze the samples were as described. The background electrolyte was prepared daily with $12 \mathrm{~m} M$ PDC and $0.55 \mathrm{~m} M$ CTAB. The $\mathrm{pH}$ of the buffer was adjusted at 3.0 with $1 M \mathrm{NaOH}$. The running buffer was filtered through $0.45-\mu \mathrm{m}$ filters; it was not necessary to degas it. The separations were carried out on fused-silica capillaries with $50 \mathrm{~cm}$ of effective length $\times 75 \mu \mathrm{m}$ i.d. at $20^{\circ} \mathrm{C}$. Before first use, a new capillary was pretreated with $0.1 \mathrm{~N} \mathrm{NaOH}$ for $10 \mathrm{~min}$, followed by water for 10 min and running buffer for 10 min. Before each run, the capillary was preconditioned with run electrolyte for $30 \mathrm{~s}$.

The sample was injected by hydrodynamic injection at 5 p.s.i. for $2 \mathrm{~s}$. The separation was performed at -25 $\mathrm{kV}$ and the wavelength for indirect UV detection was $230 \mathrm{~nm}$. The signal with negative peaks was inverted to obtain a more familiar electropherogram to integrate and process.

\section{Samples}

Raw milk was obtained from Dairy Products Technology Center (Cal Poly University, San Luis Obispo, CA). Commercial samples of whole milk, fat free milk, plain 
yogurt, Cheddar cheese, and cream cheese were purchased at local stores. Milk supernatant was collected after centrifuging raw milk at $14,000 \mathrm{rpm}$ for $20 \mathrm{~min}$, and UF milk permeate was obtained after ultrafiltrating pasteurized skim milk through 10,000 molecular weight cut-off (MWCO) filters.

\section{Sample Preparation}

Five sample buffers (SB) were tested to extract the target compounds from the milk: $\mathrm{H}_{2} \mathrm{O}$ at room temperature, $\mathrm{H}_{2} \mathrm{O}$ at $50^{\circ} \mathrm{C}$, ethanol:water (1:3), acetonitrile:water (1:1), and $4.5 \mathrm{mM} \mathrm{H} \mathrm{H}_{2} \mathrm{SO}_{4}$. The final method chosen for the preparation of the sample was simply to pipette $12 \mu \mathrm{l}$ of milk into $1 \mathrm{ml}$ of $\mathrm{H}_{2} \mathrm{O}$ containing $20 \mathrm{mg} / \mathrm{L}$ of tartaric acid as an internal standard (IS). After that, the vial containing the sample was shaken in a vortex and centrifuged at $14,000 \mathrm{rpm}$ for $30 \mathrm{~s}$ to precipitate any particle that could block the capillary. In this form, the sample was ready to run or could be frozen until analysis. It was not necessary to filter prior injection into the $\mathrm{CE}$ system. In the case of solid and semi-solid samples, $40 \mathrm{mg}$ were stirred with $10 \mathrm{ml}$ of SB for $30 \mathrm{~min}$.

\section{Analysis of Free Phosphate Content}

To compare the CE method with a standard method, we analyzed free phosphate concentrations of raw milk, milk supernatant, and UF milk permeate by a modified IDF 33C:1987 method for the determination of total phosphorous content of cheese and processed cheese products. The following method measured free inorganic phosphate, since no digestion of the OM was carried out. Two milliliters of a freshly prepared reagent containing $0.5 \%$ ammonium molybdate and $2.0 \%$ ascorbic acid was added to a $2.0-\mathrm{ml}$ aliquot of sample previously diluted to within the range of measurement. The mixture was incubated at $50^{\circ} \mathrm{C}$ for $20 \mathrm{~min}$ and cooled at room temperature for $20 \mathrm{~min}$. After that, absorbance at $820 \mathrm{~nm}$ was measured against a blank. A standard curve was prepared using desiccated $\mathrm{KH}_{2} \mathrm{PO}_{4}$.

\section{Analysis of Citric Acid in Milk}

Analysis of citric acid was carried out on raw milk, commercial whole milk, and fat-free pasteurized milk with the UV-enzymatic method for the determination of citric acid in foodstuffs and other materials (Boehringer Mannheim GmbH, Manheim, Germany). In parallel, a standard solution $(393 \mathrm{mg} / \mathrm{ml})$ of citric acid supplied with the enzymatic kit was also used to compare the results with those obtained by $\mathrm{CE}$.

\section{Validation Conditions}

Calculation of the validation parameters was based on the protocol followed by Izco et al. (1999). The ratio area/migration time of each compound against area/ migration time of IS was the response used to validate the method. The analytical conditions were the same as given above.

To determine linearity, we calculated regression lines as $y=\mathrm{a}+\mathrm{b} x$, where $x$ was concentration, and $y$ the response. Five concentration points in duplicate were used to prepare the calibration curves: $0.026,0.052$, $0.104,0.26$, and $0.52 \mathrm{mM}$ in the case of citric acid, and $0.037,0.074,0.147,0.367$, and $0.735 \mathrm{mM}$ for potassium phosphate. The indicated concentrations of both compounds were prepared from stock solutions at $1000 \mathrm{mg} /$ $\mathrm{L}$ dissolved in the sample buffer containing $20 \mathrm{mg} / \mathrm{L}$ of tartaric acid as an IS. For both compounds, the coefficients of determination $\left(\mathrm{R}^{2}\right)$ were calculated and the linearity was analyzed on the basis of the coefficient of variation values for the corresponding response factors. Detection and quantification limits were estimated as $(3 \times a / b) \times 1 / \sqrt{n}$ and $(10 \times a / b) \times 1 / \sqrt{n}$, respectively, where $a$ is the independent term of the curve, $b$ the slope, and $n$ is the number of replicates.

Intraday and day-to-day repeatability of the method was analyzed by calculating the $\mathrm{CV}$ values for the responses and retention times of six replications.

Accuracy was determined using an added external standard. A sample of milk diluted in sample buffer $(6$ $\mu \mathrm{l}$ of milk $+1 \mathrm{ml}$ of SB) with the IS was analyzed in triplicate $(\mathrm{n}=3)$ and was taken as "blank." In triplicate, three increasing known quantities of citrate and phosphate standard were then added to three aliquots of the "blank" milk sample, to yield final concentrations of: "blank" + 0.074 $\mathrm{m} M(\mathrm{n}=3)$, "blank" + $0.184 \mathrm{mM}$ (n $=3)$, and "blank" $+0.367 \mathrm{mM}(\mathrm{n}=3)$ in the case of the phosphate, and "blank" + $0.048 \mathrm{~m} M(\mathrm{n}=3)$, "blank" + $0.119 \mathrm{~m} M(\mathrm{n}=3)$, and "blank" $+0.238 \mathrm{~m} M(\mathrm{n}=3)$ in case of the citric acid. The percentage of recovery rate was established from the experimental response values [(blank + standard) - blank] obtained according to the calibration curves and the real concentration of the standard added. The CV for the recovery rates were calculated and a Student's $t$-test was applied to ascertain whether recovery was satisfactory. Furthermore, the responses obtained from the analysis of these samples plus those obtained from the analysis of the same milk sample but prepared as usually $(12 \mu \mathrm{l} \mathrm{milk}+1 \mathrm{ml}$ SB) were plotted against concentration. The $\mathrm{R}^{2}$ values calculated for these new five points regression curves were used to recognize and discard any possible interference caused by substances comigrating with any of the target compounds. 


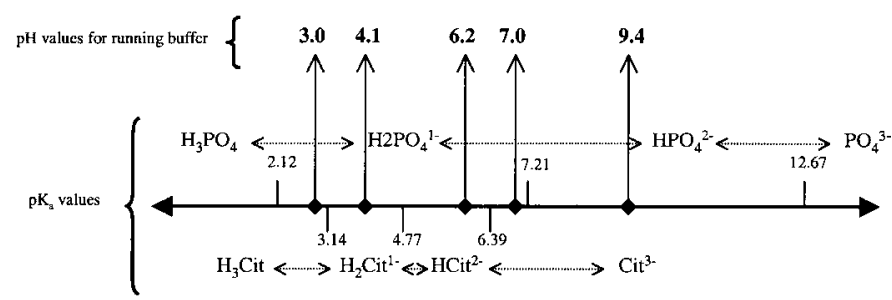

Figure 1. $\mathrm{pH}$ values selected to test the running buffers in base to the $\mathrm{pK}_{\mathrm{a}}$ values for phosphoric acid and citric acid. $\mathrm{pK}_{\mathrm{a}}$ values according to Weast et al. (1994).

\section{RESULTS AND DISCUSSION}

\section{Separation Optimization}

The choice of the background electrolyte is very important in developing a $\mathrm{CE}$ method employing indirect UV detection. In the indirect absorbance method, an absorbing electrolyte provides a background UV absorbance and comigrates with the mixture of analytes, which do not absorb at the wavelength set for the detector. The background electrolyte with a mobility matching those of most of the analytes would give a better separation and resolution (Wu et al., 1995). The electrophoretic mobility of the acids is strongly dependent on the $\mathrm{pH}$ of the running buffer. This fact is especially important in case of acids showing several $\mathrm{pK}_{\mathrm{a}}$ values. These acids can be present in different ionized forms depending on the $\mathrm{pH}$ of the buffer, and therefore it is possible to change their electrophoretic mobility. Taking into account the $\mathrm{pK}_{\mathrm{a}}$ values for citric acid and phosphoric acid (Figure 1), we tested all the $\mathrm{pH}$ values indicated in order to obtain all ionized forms for both acids to select the $\mathrm{pH}$ value yielding the best separation. As shown in Figure 2, at $\mathrm{pH} \mathrm{9.4,} \mathrm{both} \mathrm{compounds} \mathrm{were}$ resolved, but not completely. Decreasing the $\mathrm{pH}$ to 7.0 better resolution was obtained, but the peak corresponding to phosphate presented very poor symmetry, making it more difficult to quantify. At $\mathrm{pH} 6.2$, the symmetry for the mentioned peak was improved, and succinic acid was added as an IS, even though the separation between citric and the IS was poor. A good resolution between both analytes was achieved at $\mathrm{pH} 4.1$, but still it was not complete.

The best results were obtained at $\mathrm{pH}$ 3.0. In this case, PDC was used to prepare the buffer, since the minimum $\mathrm{pH}$ available with KHP was 3.95. With this new buffer and by increasing the run voltage to $-25 \mathrm{kV}$, citric acid and phosphate were totally separated and the run time was decreased to $2.3 \mathrm{~min}$, even though the order of migration of the compounds had changed.

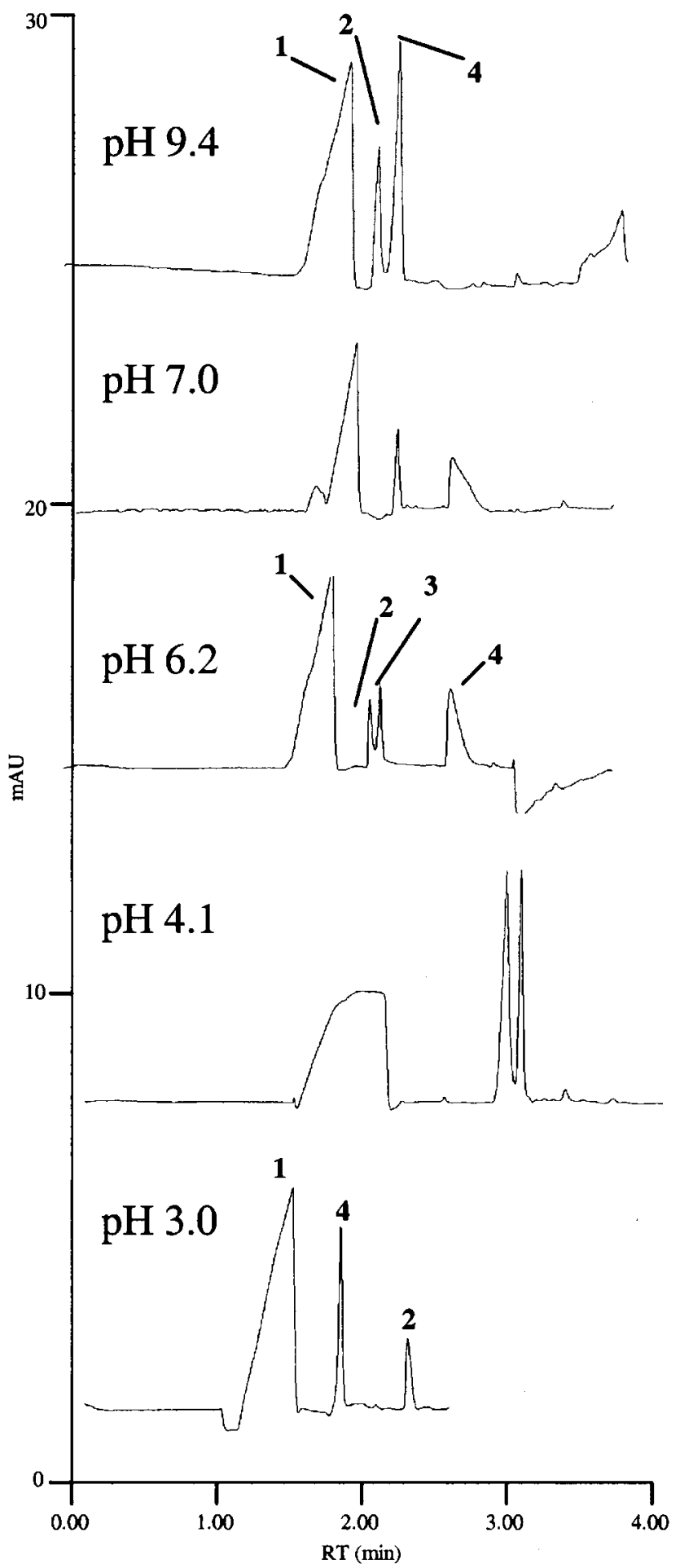

Figure 2. Effect of $\mathrm{pH}$ and type of running buffer. Milk extracted with $4.5 \mathrm{mM} \mathrm{H}_{2} \mathrm{SO}_{4}$. Run conditions for electropherograms corresponding to $\mathrm{pH}$ from 4.1 to 9.4 were as follows: running buffer was prepared with $9 \mathrm{~m} M$ potassium hydrogen phthalate and $0.027 \mathrm{mM}$ hexadecyltrimethyl ammonium bromide, run voltage at $-20 \mathrm{kV}$, detection at $\lambda=200 \mathrm{~nm}$, hydrodynamic injection at pressure (5 p.s.i.) $\times$ time $(\mathrm{s})=2 \mathrm{pH} 3.0$ running buffer was prepared with PDC (see Materials and Methods section for more details). 1: $\mathrm{H}_{2} \mathrm{SO}_{4}, 2$ : citric acid, 3: succinic acid (internal standard), 4: phosphate. 

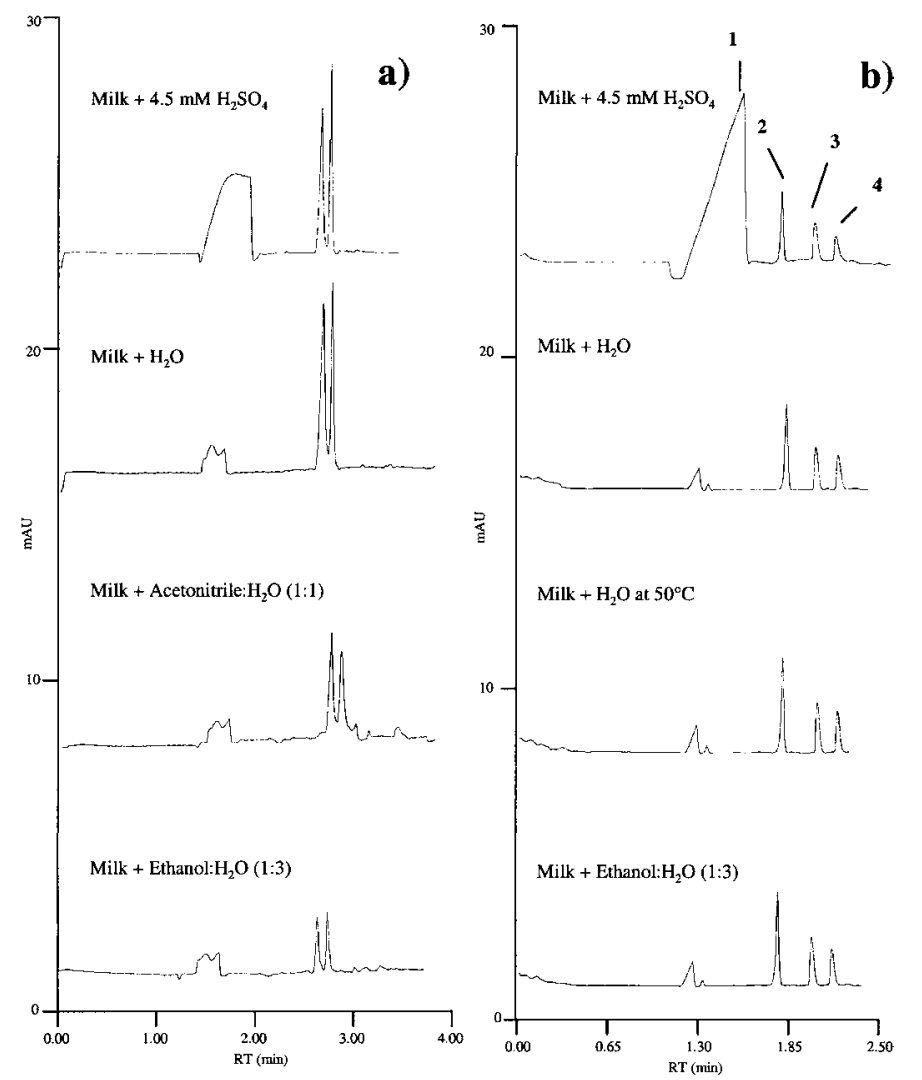

Figure 3. Effect of the sample buffer on the extraction of citrate and phosphate from milk: a) potassium hydrogen phthalate buffer at $\mathrm{pH} 4.1$, run conditions as Figure 2; b) 2,6-pyridinecarboxylic acid buffer at $\mathrm{pH}$ 3.0, run conditions as explained in Materials and Methods Section. 1: $\mathrm{H}_{2} \mathrm{SO}_{4}, 2$ : phosphate, 3: tartaric acid (internal standard), 4: citric acid.

\section{Selection of Sample Buffer}

Some methods and solvents such as ethanol: $\mathrm{H}_{2} \mathrm{O}(1: 3)$

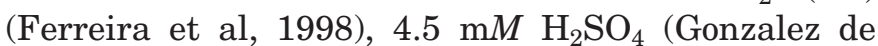
Llano, 1996), water at $50^{\circ} \mathrm{C}$ (Mullin and Emmons, 1997), and acetonitrile: $\mathrm{H}_{2} \mathrm{O}$ (1:1) (Marsili et al., 1981) have been used as SB to extract sugars and/or organic acids from dairy samples. Figure 3 shows the electropherograms corresponding to milk samples extracted with the five kind of SB tested in this work. The results obtained when using both $\mathrm{pH} 4.1 \mathrm{KHP}$ and $\mathrm{pH}$ 3.0 PDC running buffers were investigated. When analyzing milk with $\mathrm{pH} 4.1 \mathrm{KHP}$ buffer, apparently no differences

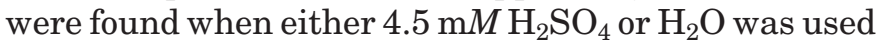
as sample buffer. However, when ethanol or acetonitrile was used to dissolve the milk, the baseline became noisier and a loss of the sensibility was detected.

In the case of PDC buffer, the results were similar for the $4 \mathrm{SB}$ shown in Figure 3, but when acetonitrile was used (electropherogram not shown) a delay in the run time was observed and the baseline became wavier.

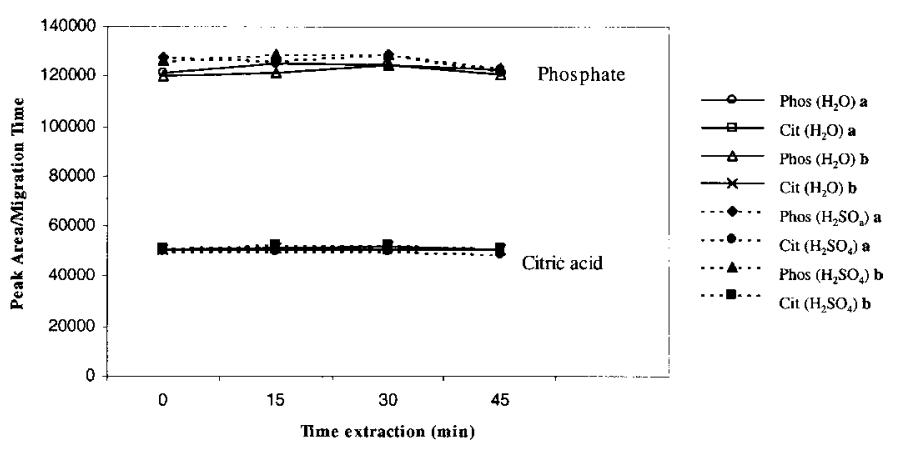

Figure 4. Effect of time of extraction of a milk sample using $\mathrm{H}_{2} \mathrm{O}$ or $\mathrm{H}_{2} \mathrm{SO}_{4}$ as sample buffer on the recovery of phosphate and citric acid. a: the sample was filtered $(0.45 \mu \mathrm{m}$ filter $)$ before running; $\mathrm{b}$ : the sample was centrifuged (14,000 rpm for $30 \mathrm{~s})$ before running.

Some authors (Marsili et al., 1981) claimed a 99\% recovery for citrate when using acetonitrile: $\mathrm{H}_{2} \mathrm{O}$ to extract organic acids from dairy products. However, acetonitrile has been compared against $\mathrm{H}_{2} \mathrm{SO}_{4}$ (FernándezGarcía and McGregor, 1994), and the recovery was much lower for the organic solvent than for sulfuric acid. Because the analyzed organic solvents showed the poorest overall results, both acetonitrile and ethanol were discarded. On the other hand, because the method used with the PDC buffer presented more advantages than that used with KHP (shorter run time, better resolution of the compounds and the possibility of using an IS appearing between both analytes), $\mathrm{PDC}$ buffer at $\mathrm{pH}$ 3.0 was used for further investigations.

\section{Extraction Procedure}

Because the first objective of this work was to find a simple and quick method for our application, some variables were studied to simplify as much as possible the extraction and further treatment of the sample.

A milk sample was extracted during $1 \mathrm{~h}$ with three solvents separately: $\mathrm{H}_{2} \mathrm{O}$ at room temperature, $\mathrm{H}_{2} \mathrm{O}$ at $50^{\circ} \mathrm{C}$ and $4.5 \mathrm{mM} \mathrm{H} \mathrm{SO}_{4}$. No differences were found between them $(P<0.01)$, with mean values of $21.34 \pm$ 0.39 and $7.61 \pm 0.16 \mathrm{~m} M$ for phosphate and citric acid, respectively. In the same form, milk being extracted for $1 \mathrm{~h}$ was sampled every $15 \mathrm{~min}$ to study the recovery over time. In parallel, an aliquot was filtered through $0.45-\mu \mathrm{m}$ filter before running it in the CE System, and other aliquot was centrifuged for $30 \mathrm{~s}$ at $14,000 \mathrm{rpm}$. Figure 4 shows the responses of phosphate and citric acid during the time of extraction using $\mathrm{H}_{2} \mathrm{O}$ and 4.5 $\mathrm{m} M \mathrm{H}_{2} \mathrm{SO}_{4}$ as sample buffers. No differences were found over time and therefore, the time of extraction could be reduced from $1 \mathrm{~h}$ to time zero, which means that the sample was ready to analyze immediately after 
Table 1. Regression equations for the calibration curves and results of the analysis of the linearity, and intraday $(n=6)$ and day-to-day $(n=6)$ repeatability for phosphate and citric acid, using $\mathrm{H}_{2} \mathrm{O}$ or $\mathrm{H}_{2} \mathrm{SO}_{4}$ as sample buffer.

\begin{tabular}{|c|c|c|c|c|}
\hline \multirow{2}{*}{$\begin{array}{l}\text { Sample buffer } \\
\text { Compound }\end{array}$} & \multicolumn{2}{|c|}{$\mathrm{H}_{2} \mathrm{O}$} & \multicolumn{2}{|c|}{$\mathrm{H}_{2} \mathrm{SO}_{4}$} \\
\hline & Phosphate & Citric acid & Phosphate & Citric acid \\
\hline Regr. Equation & $y=7.2512 X-0.042$ & $y=8.5078 X-0.00009$ & $y=6.9086 X+0.0215$ & $y=8.3326 X-0.0292$ \\
\hline $\mathrm{R}^{2}$ & 0.9998 & 0.9993 & 0.9997 & 0.9999 \\
\hline $\mathrm{CV}$ of $f^{1}(\%)$ & 3.00 & 2.95 & 3.86 & 3.89 \\
\hline Detec. limit ${ }^{2}$ & $5.1 \cdot 10^{-3}$ & $2.4 \cdot 10^{-3}$ & $6.6 \cdot 10^{-3}$ & $7.4 \cdot 10^{-3}$ \\
\hline Quantif. limit $^{2}$ & $1.7 \cdot 10^{-2}$ & $0.8 \cdot 10^{-2}$ & $2.2 \cdot 10^{-2}$ & $2.5 \cdot 10^{-2}$ \\
\hline Concentration $^{3}$ & 21.02 & 7.39 & 21.74 & 7.81 \\
\hline CV intraday ${ }^{4}$ & 4.56 & 3.89 & 4.82 & 3.17 \\
\hline CV day-to-day ${ }^{4}$ & 4.40 & 4.11 & 8.09 & 6.99 \\
\hline Retention time ${ }^{5}$ & 1.85 & 2.27 & 1.87 & 2.31 \\
\hline CV intraday ${ }^{4}$ & 0.24 & 0.48 & 0.48 & 0.36 \\
\hline CV day-to-day ${ }^{4}$ & 2.69 & 3.00 & 3.89 & 4.43 \\
\hline
\end{tabular}

diluting the milk with SB, independently of the SB used. Moreover, no significant decrease in the concentration of any of the compounds was detected when filtering (to eliminate gross particles) or centrifuging (to degas) the sample. Consequently, we could confirm that the fraction of the target compounds located in the micelles and measurable by this technique was not affected by these pretreatments, possibly because those pretreatments did not cause a significant precipitation and/or loss of the micelles of casein. In fact, a milk sample was run without filtering or centrifuging, and the quantity of these compounds remained the same. However, we recommend at least centrifuging the sample for $30 \mathrm{~s}$ after diluting with SB (which is cheaper and faster than filtering) in order to precipitate any possible particle that could block the capillary.

\section{Validation}

Linearity. Table 1 shows the results of the analysis of linearity for both compounds with $\mathrm{H}_{2} \mathrm{O}$ or $4.5 \mathrm{mM}$ $\mathrm{H}_{2} \mathrm{SO}_{4}$ as $\mathrm{SB}$ to prepare the calibration curves. For both buffers, the values of $R^{2}$ obtained were excellent (better than 0.999$)$. To verify the linearity of the regression lines, the response factors $(\boldsymbol{f})$ were calculated by dividing the response of the peak obtained in the electropherogram and the corresponding concentration. The CV values of $f$ were in the range 0 to $5 \%$, considered adequate to verify the linearity of regression lines for an analytical method (Castro et al., 1989). Nevertheless, when sulfuric acid was used as SB, higher deviation for $f$ were detected and higher detection and quantification limits were calculated. This deviation probably caused the high concentration of sulfuric acid in the sample (biggest peak of the electropherogram, see Figure 2), which increased the ionic strength inside the capillary, affecting the definition of the peaks, especially that corresponding to phosphate, and making the quantification more difficult.

Precision. As expected, the deviation of the retention times obtained in different days (Table 1) was higher than the deviation observed intraday, even though the values calculated were low. This is logical, since small changes when the running buffer is prepared can affect the retention times of the analytes. However, that low deviation found in the retention time did not significantly affect the concentration of phosphate and citric acid measured when $\mathrm{H}_{2} \mathrm{O}$ was used as $\mathrm{SB}$, since the $\mathrm{CV}$ values calculated remained practically the same intraday or day to day. The values recorded are in the range accepted $(\mathrm{CV}<4$ to $5 \%)$ when examining precision for analytical methods on an overall basis (Izco et al., 1999). In our case, the CV values of Table 1 represent the repeatability for the full method, including the sample preparation. However, when this factor was eliminated, and the same sample was run six straight times, CV values lower than $1 \%$ were obtained. This fact implies that the first source of variation of the proposed method was to pipette the $12 \mu \mathrm{l}$ of milk into the SB. Nevertheless, since the speed of analysis was an issue in our work and the CV values derived were acceptable (less than 5\%), we preferred using the outlined procedure instead of using volumetric flasks that might reduce the error due to the sample dilution.

The results obtained when sulfuric acid was SB were poorer than those recorded when $\mathrm{H}_{2} \mathrm{O}$ was used to pre- 
Table 2. Results of the analysis of accuracy.

\begin{tabular}{llccc}
\hline Sample & $\begin{array}{l}\text { Phosphate } \\
\text { added }^{1}\end{array}$ & $\begin{array}{l}\text { Phosphate } \\
\text { recovery }\end{array}$ & $\begin{array}{l}\text { Citrate } \\
\text { added }^{1}\end{array}$ & $\begin{array}{l}\text { Citric acid } \\
\text { recovery }\end{array}$ \\
\hline Blank $(\mathrm{n}=3)$ & & $\ldots$ & & $\ldots$ \\
$R_{1}\left(\operatorname{Blank}+\operatorname{Std}_{1}\right)(\mathrm{n}=3)$ & 0.074 & 96.5 & 0.048 & 95.2 \\
$R_{2}\left(\right.$ Blank $\left.^{2} \mathrm{Std}_{2}\right)(\mathrm{n}=3)$ & 0.184 & 104.9 & 0.119 & 100.0 \\
$R_{3}\left(\right.$ Blank $\left.+\mathrm{Std}_{3}\right)(\mathrm{n}=3)$ & 0.367 & 108.2 & 0.238 & 105.7 \\
$\mathrm{R}$ & & 103.2 & & 100.3 \\
$\mathrm{CV}$ & & 5.9 & & 5.3 \\
$t_{\text {Student }}=[(|100-\bar{R}| \cdot \sqrt{n}) / \mathrm{RSD}]$ & 0.95 & & 0.09 \\
$t_{(0.05,2)}$ & 4.30 & & 4.30 \\
\hline
\end{tabular}

${ }^{1}$ Phosphate and citrate standard added to milk $\left(\mathrm{Std}_{1}, \mathrm{Std}_{2}\right.$ and $\left.\mathrm{Std}_{3}\right)$ are in $\mathrm{m} M$. Blank = milk diluted in sample buffer $(6 \mu \mathrm{l}$ milk $+1 \mathrm{ml} \mathrm{SB}) \cdot R_{1}, R_{2}$ and $R_{3}=$ Recovery rate $(\%) \cdot \overline{\mathrm{R}}=$ total recovery rate, $\mathrm{CV}=$ coefficient of variation $(\%)$ of $\bar{R}$.

pare the sample. This result is especially noticeable when day-to-day repeatability was studied. Because of that and because, in general, no differences were detected in the recovery compared with water (data not shown), sulfuric acid was discarded as sample buffer.

Accuracy. The accuracy of the method was analyzed by the addition of increasing known concentrations of phosphate and citric acid standards, as explained in Materials and Methods. A milk sample diluted in the SB ( $6 \mu$ of milk $+1 \mathrm{ml}$ of SB) was used as blank. Three replications were performed for the blank and also for each of the increasing quantities of standard added. The mean recovery rate and the $\mathrm{CV}$ values for the recovery rates were calculated for each compound. As shown in Table 2, total recovery for phosphate and citric acid is 103.2 and $100.3 \%$, respectively. Also, applying a Student's $t$-test to each of the two analytes failed to yield any significant differences in the percentage recovery rates recorded and $100 \%$, which means that the recovery for both compounds were close to $100 \%$. The results obtained are better than those found in other work where organic acids were analyzed by HPLC and the extraction with sulfuric acid yielded a percentage of recovery for citric acid of $78.4 \%$ in milk (González de Llano et al., 1996) or 90.3 to $94.6 \%$ in yogurt (Fernández-García and McGregor, 1994). With CE to analyze organic acids, $107 \%$ of recovery from a rubber sample was calculated for citric acid using CTAB with phosphate as running buffer (Galli et al., 2000).

Furthermore, the responses obtained for the blank, the three increasing concentrations of standard added to the blank, plus a milk sample prepared as usually (12 $\mu \mathrm{l} \mathrm{milk}+1 \mathrm{ml} \mathrm{SB}$ ) were plotted versus the concentration added (in case of standard) or calculated (in case of blank or milk). In this form, the coefficients of determination $\left(\mathrm{R}^{2}\right)$ for these two new regression lines for phosphate and citric acid were 0.9933 and 0.9967 , respectively. This means that the response for phosphate and citrate in milk increased linearly with the concentration of standard added, and, therefore, no significant inter- ference of any compound could comigrate with any of them as a single peak in the electropherogram.

In addition, some commercial samples and a standard at a known concentration were analyzed using an enzymatic kit to analyze citric acid in food samples. The results were similar by both methods, with a deviation less than 5\% (Table 3). Moreover, the quantities recorded were in the normal range (7 to $11 \mathrm{mM}$ ) for total concentration of citric acid in milk (Walstra et al., 1999). In milk, most of the citrate $(90 \%)$ is present in the serum, forming relative soluble complexes with $\mathrm{Ca}$ and $\mathrm{Mg}$, and most of the rest is contained in the micelles of casein as colloidal particles (Walstra et al., 1999). Some of the citrate present is in an insoluble form in the sample after dissolving it in the $\mathrm{SB}\left(\mathrm{H}_{2} \mathrm{O}\right)$. However, once the sample was injected into the capillary and mixed with the acid running buffer $(\mathrm{pH} 3.0)$, all the citrate appeared to be completely dissolved and recovered for its detection. This could explain why no differences were found with $\mathrm{H}_{2} \mathrm{SO}_{4}$ or $\mathrm{H}_{2} \mathrm{O}$ as $\mathrm{SB}$.

Table 4 shows the results obtained in the analysis of phosphate by $\mathrm{CE}$ and by a colorimetric method. Some samples were analyzed by both methods: raw milk, supernatant obtained from the same raw milk, and UF permeate obtained from pasteurized milk. Phosphate is present in milk in five forms: inorganic dissolved, inorganic colloidal, water-soluble esters, and esterified with caseins and lipids (Jenness, 1988), with an approximate distribution in milk of $36,32,9,22$, and $1 \%$, respectively (Walstra et al., 1999). The analysis of milk by $\mathrm{CE}$ yielded a concentration of $20.4 \mathrm{mM}$, which matches with the normal values of inorganic phosphate in milk: 19 to $23 \mathrm{mM}$ (Walstra et al., 1999). However, the concentration measured with the colorimetric method was much lower $(11.6 \mathrm{mM})$. This is logical, since the colorimetric method measured only the inorganic free phosphate (no digestion of sample was carried out). In fact, the deviation between both values is $43.2 \%$ (Table 4), which is close to the $48 \%$ that, according to Walstra et al. (1999), colloidal phosphate accounts 
Table 3. Analysis of citric acid by capillary electrophoresis (CE) and by an enzymatic method (n = 2).

\begin{tabular}{lccl}
\hline Sample & $\mathrm{CE}(\mathrm{m} M)$ & Enz. kit $(\mathrm{m} M)$ & Deviation $(\%)$ \\
\hline Raw milk & $8.3 \pm 0.1$ & $8.4 \pm 0.3$ & 0.5 \\
Commercial whole milk & $9.4 \pm 0.1$ & $9.8 \pm 0.2$ & 4.6 \\
Commercial fat-free milk & $8.5 \pm 0.3$ & $9.0 \pm 0.1$ & 4.8 \\
Standard $(393 \mathrm{mg} / 100 \mathrm{ml})$ & $20.7 \pm 0.1$ & $20.5 \pm 0.1$ & -0.8 \\
\hline
\end{tabular}

versus dissolved phosphate. When centrifuging the milk sample for a long time, a part of the micelles of casein were precipitated, and, therefore, a loss of phosphate was detected. In case of the colorimetric method, a decrease was also observed. Since the colorimetric method measures free dissolved phosphate-perhaps during the dilution of the sample to within the range of measurement-the equilibrium between the two kinds of inorganic phosphates is broken, and some of the colloidal phosphate is dissolved.

When filtering skim milk to obtain UF permeate, all the proteins with molecular weight larger than 10,000 (including the micelles containing colloidal phosphate) remained on the filter. In this case, only the inorganic dissolved phosphate was present in the sample. Consequently, only inorganic dissolved phosphate was analyzed, and the same results were observed by both analytical techniques (Table 4).

\section{Application to Other Dairy Products}

To study the suitability of the technique to determine the concentration of phosphate and citric acid in other products, some commercial samples of yogurt, Cheddar cheese, and cream cheese were analyzed (Figure 5). Some unknown peaks appear in the electropherogram, which probably are organic acids (such as acetic or formic) produced during fermentation (Izco et al., 2002). To establish whether these or other compounds could comigrate with our target peaks interfering the quantification, we added some increasing concentrations of phosphate and citric acid standards to the samples. In the same manner as in the study of the accuracy carried out for the milk, new regression lines were plotted, and the $\mathrm{R}^{2}$ calculated for these curves are shown in Table 5. In all cases, the response in the CE system increased linearly with the concentration added, which means that no significant interference with the target com- pounds was detected. Nevertheless, it must be considered that this CE method utilizes indirect UV detection, and the background running buffer is what makes the detection possible. Compounds with same retention time could show the same intensity of the signal under the detector. This fact could mask the presence of other organic acids (e.g., concentration values of formic, acetic, or lactic acid in the kind samples tested are higher than the normal values found in milk) comigrating with phosphate and/or citrate.

The concentration calculated agreed with the data found in the literature. In Cheddar cheese, $1.75 \mathrm{mg} / \mathrm{g}$ $(0.18 \% \mathrm{wt} / \mathrm{wt})$ of citric acid was measured (Table 5). Citric acid is not the first energy source of bacteria, but can be metabolized very rapidly by Lactococcus Lactis subsp. diacetylactis or Leuconostoc spp. in Cheddar cheese. Depending on the starter used, citrate can remain constant at $2 \%(\mathrm{wt} / \mathrm{wt})$ up to 3 mo of ripening, and decrease to $0.1 \%$ (wt/wt) at 6 mo (Fox, 1993). Mullins and Emmons (1997) detected 2.10 to $2.13 \mathrm{mg} / \mathrm{g}$ of citric acid in water-soluble fraction of several commercial Cheddar cheeses analyzed by HPLC. In the case of yogurt, the quantity of citric measured $(2.3 \mathrm{mg} / \mathrm{g})$ is similar to other results recorded in the literature (Fernández-García and McGregor, 1994).

The concentrations of phosphate measured in yogurt, Cheddar cheese and cream cheese were 2.22, 7.44, and $1.18 \mathrm{mg} / \mathrm{g}$, respectively. During cheese ripening, the caseins are cleaved by rennet, plasmin, and bacterial proteinases into phosphorous-rich peptides. However, complete casein degradation can be achieved only by the combined action of proteinases and phosphatases present in cheese (Fox, 1993). Therefore, due to the action of the phosphatases and proteases during ripening, some of the esterified phosphate is released and detected by the CE. The phosphate residues bound to peptides exert a protective effect against further proteolysis (Fox, 1993). Consequently, the proposed method

Table 4. Analysis of phosphate by capillary electrophoresis (CE) and by a colorimetric method $(n=2)$.

\begin{tabular}{llll}
\hline Sample & CE $(\mathrm{m} M)$ & $\begin{array}{l}\text { Colorimetric } \\
\text { method }(\mathrm{m} M)\end{array}$ & Deviation $(\%)$ \\
\hline Raw milk & $20.4 \pm 0.7$ & $11.6 \pm 0.5$ & 43.2 \\
Raw milk supernatant & $12.3 \pm 0.3$ & $8.66 \pm 0.6$ & 29.4 \\
UF Pasteurized milk permeate & $12.5 \pm 0.1$ & $12.5 \pm 0.1$ & -0.04 \\
\hline
\end{tabular}


Table 5. Analysis of commercial samples, $\mathrm{R}^{2}$, and recovery obtained when adding increasing quantities of standard to the sample.

\begin{tabular}{llllllr}
\hline Sample & $\begin{array}{l}\text { Phosphate } \\
\text { quantified }^{1}\end{array}$ & $\mathrm{R}_{\text {phosphate }}{ }^{2}$ & Recov. $^{3}$ & $\begin{array}{l}\text { Citric acid } \\
\text { quantified }^{1}\end{array}$ & $\mathrm{R}_{\text {citric acid }}{ }^{2}$ & Recov. $^{3}$ \\
\hline Yogurt & $2.22 \pm 0.15$ & 0.9982 & 96.0 & $2.30 \pm 0.1$ & 0.9982 & 99.6 \\
Cheddar cheese & $7.44 \pm 0.44$ & 0.9892 & 93.0 & $1.75 \pm 0.15$ & 0.9993 & 93.5 \\
Cream cheese & $1.18 \pm 0.02$ & 0.9977 & 98.0 & $1.15 \pm 0.03$ & 0.9963 & 106.0 \\
\hline
\end{tabular}

${ }^{1}$ Phosphate and citrate quantified in the samples are in $\mathrm{mg} / \mathrm{g}$.

${ }^{2} \mathrm{R}^{2}$ obtained when plotting increasing quantities of standard added to the sample versus response.

${ }^{3}$ Percentage recovery $(\%)$.

could be helpful in rapidly analyzing the phosphate released during ripening of cheese. Perhaps, it could be a useful tool to test the effect of phosphatases together

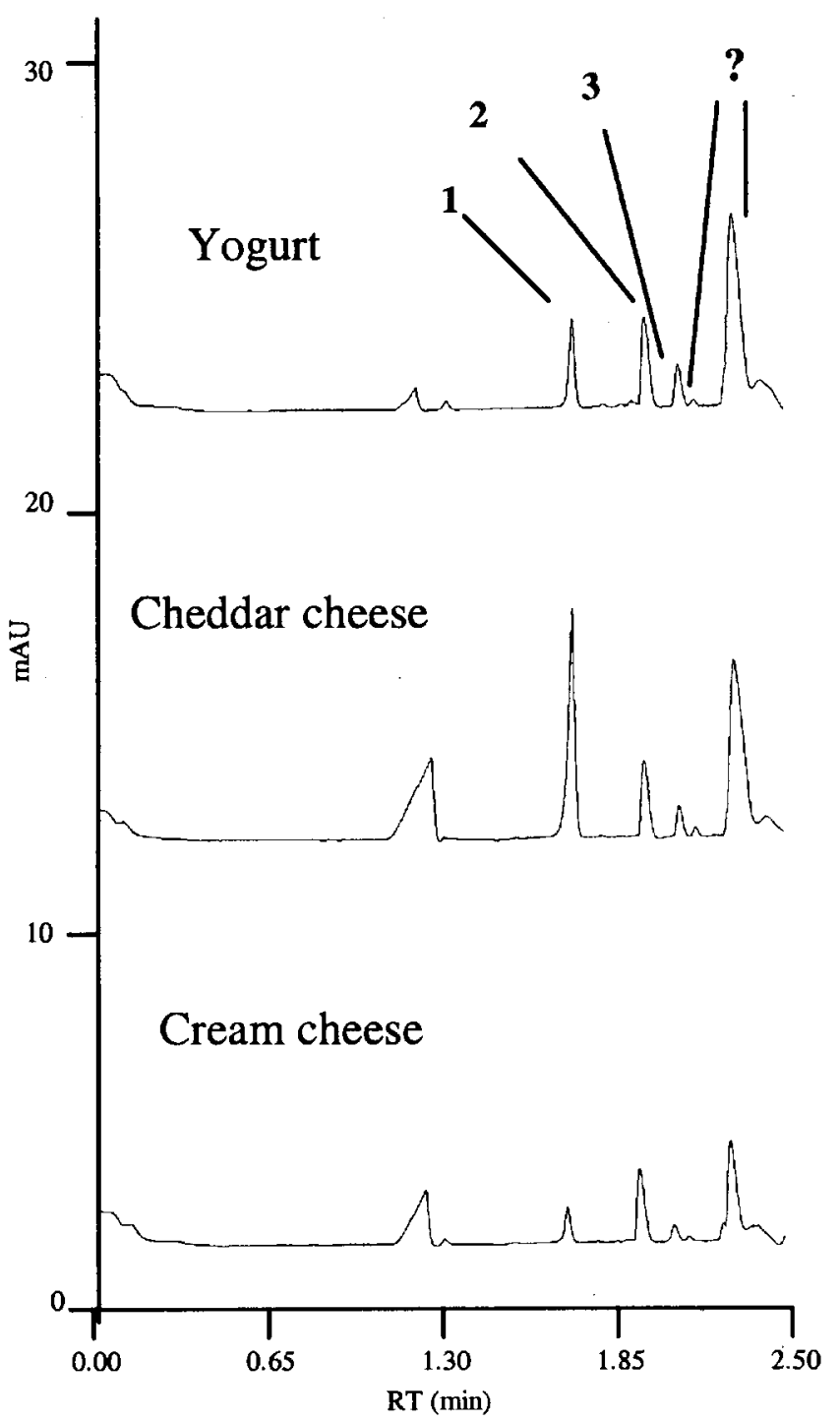

Figure 5. Electropherograms of some commercial samples. 1: phosphate, 2: tartaric acid (IS), 3: citric acid, ?: Unknown. with proteolytic enzymes (especially peptidases) added during the cheese-making process to accelerate the ripening of cheese.

\section{CONCLUSIONS}

In summary, $\mathrm{CE}$ is well suited to the analysis of inorganic phosphate and citric acid in milk and appears to be a good alternative to other analytical techniques. It seems applicable to other dairy matrices such as yogurt, Cheddar cheese, and cream cheese. Also, CE has been shown to achieve adequate separations and the reliability of the technique has been verified by analysis of linearity, precision, and accuracy. Capillary electrophoresis provides the additional advantages of low solvent consumption (more than four samples can be run with only $1 \mathrm{ml}$ of buffer, which means milliliters per day vs. liters per day for HPLC) and short analysis time ( 2.3 min vs. more than $1 \mathrm{~h}$ to analyze phosphate by official methods). Also, hazardous solvents are used and the costs are low compared with other analytical techniques (more than 3000 analyses were run with the same capillary without loss of resolution, but only 30 analyses can be performed with the kit to determine citric acid; in the case of HPLC, columns must be deeply cleaned and regenerated after a few analyses). The procedure is rapid and offers fast and simple sample preparation. Once the sample has arrived at the laboratory, less than 5 min (including handling, preparation, running, integration and quantification) is necessary to determine the concentration of citric acid and inorganic phosphate.

In forthcoming studies, we will use this method on a large number of milk samples collected from several dairy plants periodically over $1 \mathrm{yr}$. The aim of this work will be to test the buffering capacity of milk and determine whether there is any correlation with the concentration of these compounds.

\section{ACKNOWLEDGMENTS}

The authors are very grateful to the Secretaría de Estado de Educación, Universidades, Investigación y 
Desarrollo of the Ministry of Education and Culture of Spain, and to California Dairy Research Foundation for the funding provided for this study.

\section{REFERENCES}

AOAC. International. 1995. Official methods of analysis. P. Cunnif, ed. A.O.A.C. International, Gaithersburg, MD.

Castro, M., S. Gascon, M. Pujol, J. M. Sans, and P. Vicente. 1989. Validation of Analytical Methods. Monografia de la Asociacion Espanola de Farmaceuticos de la Industria, Seccion Catalana, Comision de Normas de Buena Fabricacion y Control de Calidad, ed. Hewlett-Packard, Barcelona, Spain.

Emmons, D. B., C. A. Ernstrom, C. Lacroix, and P. Sauve. 1993. Further considerations in formulas for predicting cheese yield from the composition of milk. J. Dairy Sci. 76:914-920.

Fernández-García, E., and J. U. McGregor. 1994. Determination of organic acids during the fermentation and cold storage of yogurt. J. Dairy Sci. 77:2934-2939.

Ferreira, I. M. P. L. V. O., A. M. P. Gomes, and M. A. Ferreira. 1998. Determination of sugars, and some other compounds in infant formulae, follow-up milks and human milk by HPLC-UV/IR. Carbohydr. Polymers 37:225-229.

Fox, P. F., J. Law, P. L. H. McSweeney, and J. Wallace. 1993. Biochemistry of cheese ripening. Pages 389-438 in Cheese: Chemistry, Physics and Microbiology. P.F. Fox, ed. Chapman \& Hall, London, UK.

Galli, V., N. Olmo, and C. Barbas. 2000. Development and validation of a capillary electrophoresis method for the measurement of short-chain organic acids in natural rubber latex. J. Chromatogr. A 894:135-144.

González de Llano, D., A. Rodríguez, and P. Cuesta. 1996. Effect of lactic starter cultures on the organic acid composition of milk and cheese during ripening-analysis by HPLC. J. Appl. Biotechnol. 80:570-576.

Holt, C. The Milk Salts and their Interactions with Casein. 1997. Pages 233-256 in Advanced Dairy Chemistry. Volume 3: Lactose, Water, Salts, and Vitamins. P. F. Fox, ed. Chapman \& Hall, London, UK.

International IDF Standard 33C:1987. Cheese and processed cheese products, Determination of Total Phosphorus content (Photometric method), Brussels, Belgium.

Izco, J. M., M. I. Ordóñez, P. Torres, and Y. Barcina. 1999. Validation of Capillary Electrophoresis in the analysis of ewe's milk casein. J. Chromatogr. A 832:239-246.
Izco, J. M., M. Tormo, and R. Jimenez-Flores. 2002. Development of a CE method to analyze organic acids in dairy products. Application to study the metabolism of heat-shocked spores. J. Agric. Food Chem. 50:1765-1773.

Jenness, R. 1988. Composition of milk. Pages 1-38 in Fundamentals of Dairy Chemistry. N. P. Wong, ed. Van Nostrand Reinhold Company, New York.

Kirchmeier, O. 1980. Pufferkapzitaten und puffergleichgewichte der milch. Milchwissenschaft 35:667-670.

López-Fandiño, R., M. A. De la Fuente, M. Ramos, and A. Olano. 1998. Distribution of minerals and proteins between the soluble and colloidal phases of pressurized milks from different species. J. Dairy Res. 65:69-78.

Lucey, J. A., C. Gorry, and P. F. Fox. 1993a. Acid-base buffering of milk. Milchwissenschaft 48:268-272.

Lucey, J. A., C. Gorry, and P. F. Fox. 1993b. Importance of calcium and phosphate in cheese manufacture: A review. J. Dairy Sci. 76:1714-1724.

Marsili, R. T., H. Ostapenko, R. E. Simmons, and D. E. Green. 1981. High performance liquid chromatographic determination of organic acids in dairy products. J. Food Sci. 46:52-57.

McGaan, C. A., W. Bucheim, R. D. Kearney, and T. Richardson. 1993. Composition and ultrastructure of calcium-phosphate-citrate complexes in bovine milk systems. Biochim. Biophys. Acta 760:415-420.

Mullin, W. J., and D. B. Emmons. 1997. Determination of organic acids and sugars in cheese, milk and whey by high performance liquid chromatography. Food Res. Int. 30:147-151.

Swaisgood, H. E. 1985. Characteristics of edible fluids of animal origin: Milk. Pages 791-828 in Food Chemistry. O. R. Fennema, ed. Marcel Dekker Inc, New York.

Singh, H., O. J. McCarthy, and J. A. Lucey. 1997. Physio-Chemical Properties of Milk. Pages 469-518 in Advanced Dairy Chemistry. Volume 3: Lactose, Water, Salts, and Vitamins. P. F. Fox, ed. Chapman \& Hall, London, UK.

Srilaokul, S., L. Ozimek, F. Wolfe, and J. Dziuba. 1989. The effect of ultrafiltration on physicochemical properties of retentate. Can. Inst. Food Sci. Technol. J. 5:56-62.

Unnikrishnan, V., and K. D. V. V. Doss. 1982. Effect of citrate and calcium contents on buffer capacity of cow's milk. Asian J. Dairy Res. 1:82-87.

Walstra, P., T. J. Geurts, A. Noomen, A. Jellema, and M. A. J. S. van Boekel. 1999. Dairy technology: principles of milk properties and processes. Marcel Dekker Inc., New York.

Weast, C. R., J. M. Astle, and H. W. Beyer. 1984. Handbook of chemistry and physics. 64th ed. CRC Press Inc., Boca Raton, FL.

Wu, C. H., Y. S. Lo, Y.-H. Lee, and T.-I. Lin. 1995. Capillary electrophoresis determination of organic acids with indirect detection. J. Chromatogr. A 716:291-301. 